\title{
AS DIFICULDADES DE VINCULAÇÃO DA DECISÃO JUDICIAL AOS PRECEDENTES. NECESSIDADE DE IR ALÉM DE UMA ABORDAGEM DESCRITIVISTA DA TEORIA DA DECISÃO
}

\section{THE DIFFICULTIES ON LINKING JUDICIAL DECISIONS TO PRECEDENTS. THE NEED FOR GOING BEYOND A DESCRIPTIVIST APPROACH OF THE DECISIONS THEORY}

\author{
${ }^{1}$ Giovanni Magalhães Porto \\ ${ }^{2}$ Laryssa de Almeida Donato
}

\section{RESUMO}

Este trabalho examinará, sem qualquer pretensão de exaurir o tema, o problema causado pelas dificuldades práticas de vinculação da magistratura de primeiro grau aos precedentes dos tribunais superiores que, atualmente, se coloca como fórmula mágica em todo processo de reforma da legislação referente ao regramento do desenvolvimento da decisão judicial. O reconhecimento de que o direito é construído, pelos juízes, a cada dia e a cada decisão, como práxis, torna desde logo perceptível a dificuldade de engessamento dessa atividade pela assunção de stare decisis, como marcadores hermeticamente fechados para a expansão do entendimento sobre a dogmática. Considerando a Teoria da Decisão Judicial sob a ótica do realismo jurídico estadunidense, com destaque na obra de Benjamin N. Cardozo, observar-se- á que a concepção descritivista é insuficiente a exigir que se ultrapasse os limites dogmáticos para a análise conjuntural e zetética que permita se chegar a uma abordagem prescritivista de como os juízes deveriam decidir. Neste contexto, se utilizará da teoria dos moral rights de Dworkin em relação a efetividade da decisão, pois mesmo se tendo redefinido o conceito de discricionariedade, ainda foi insuficiente, por desprezar o olhar pragmatista do futuro, que permitiria a melhor compreensão dos princípios comunitários e dos padrões comportamentais utilizados pelos magistrados nos caldeirões dos tribunais. Na verdade a criação do direito, não é portanto mecânica ou desregrada mas decorre de uma experiência específica vivenciada pelo magistrado, capaz de reconhecer muito mais do que o legislador, ou do entendimento das altas cortes que são impedidos de verem fatos, as circunstâncias envolvidas no conflito social, permitindo conhecer e resolver as particularidades para apontar para as deficiências do regramento vinculante do precedente que não apenas pode, mas deve ser modificado diante da necessidade de se melhorar cada vez mais a interpretação autêntica por excelência.

Palavras-chave: Decisão judicial, Modificação dos precedentes, Além do descritivismo

\author{
ABSTRACT

\footnotetext{
${ }^{1}$ Doutorando em Direitos Humanos pela Universidade Federal da Paraiba. Juiz de Direito Titular do Juizado Especial Criminal de Campina Grande. Universidade Federal da Paraiba - UFPB, João Pessoa, Paraíba. Brasil E-mail: gmporto@uol.com.br

2 Especialização em Direito processual e do trabalho pela Universidade Anhanguera-Uniderp. Universidade Anhanguera - Uniderp, Campo Grande, Mato Grosso do Sul. Brasil - E-mail: laryssadonatoo@gmail.com
} 
The current work intends to examine, without any pretension of exhausting the topic, the problem caused by linking practical difficulties of first degree judiciary to previous higher courts that currently stands as magic formula around the law reform process regarding the

establishment of rules of development of judicial decision. The recognition that the right is built by the law judges, every day and every decision, as praxis, becomes immediately apparent the difficulty of immobilization of this activity by the assumption of stare decisis, as hermetically markers to expand the understanding of the dogmatic. Considering the Theory of Judicial Decision from the perspective of American legal realism, particularly in the work of Benjamin N. Cardozo, it will be observed that the descriptivist design is insufficient to require going beyond the dogmatic limits for conjunctural and zetética analysis allow to reach a prescriptive approach to how judges should decide. In this context, use of the theory of moral rights of Dworkin compared the effectiveness of decision because even if having redefined the concept of discretion, was still insufficient, despises the pragmatist look of the future, which would allow better understanding of Community principles and behavioral standards used by judges in "cauldrons of the courts". In fact the creation of law, is not so mechanical or unruly but derives from a specific experience lived by the magistrate, able to recognize much more the legislature, or the understanding of the supreme courts are prevented from seeing facts, circumstances involved in social conflict, allowing to know and solve the specifics to point to the shortcomings of the previous binding regulation that not only may, but it must be modified before the need to improve more and more the authentic by excellence.

Keywords: Judicial decision, Precedent modification, Beyond descriptivism 


\section{Introdução}

O presente artigo, objetiva examinar, sob o enfoque do Realismo Jurídico norte americano, o problema da falsa noção de segurança jurídica decorrente do atavismo da vinculação do direito aos precedentes ${ }^{1}$ que, hoje, se coloca na ordem do dia em nosso país, notadamente, a partir da Reforma no Judiciário pela Emenda Constitucional no 45/04, e das diversas modificações na legislação processual civil subsequente ${ }^{2}$, com a instituição paulatina de sistemas ${ }^{3}$ cada vez mais vinculatórios ao ato de decidir que tornam os magistrados menos intérpretes e mais replicadores de regras pré-fixadas e estanques.

Neste contexto, o ato decisional parece cada dia mais voltado para a abordagem descritivista, vinculado à dogmática do que a consideração de qualquer fundamento zetético e portanto prescritivista, pois essa última esfera do conhecimento ficaria vedada a consideração da magistratura de primeiro grau, reservada tão somente aos magistrados do Supremo Tribunal Federal ou aos estudiosos da academia que vão além da docência por manuais.

Esse equívoco em separar a dogmática da zetética repisa o problema já conhecido pela clássica distinção entre o direito como estrutura lógica ou fenômeno histórico, dicotomia presente no estudo da "Velha e da Nova Ciência do Direito", como advertido por Nelson Saldanha, que percebeu o erro na pressuposição "estranha e amesquinhadora" dos dogmáticos em se excluir a história do corpus o saber jurídico, pois ela corresponderia ao seu caráter de ethos da convivencialidade, refletindo no processo de autocrítica inerente ao saber jurídico (SALDANHA, 1974, p.33 e 43).

Há modernamente um distanciamento entre a academia e os tribunais, como bem percebido por Richard Posner (2011, 229-258) ao afirmar que os juízes não são professores de direito e desta forma estariam distantes das críticas dos últimos, o que não ocorria na fase áurea do Realismo Jurídico Americano, quando os magistrados como Cardozo, Holmes, Brandeis, Cardozo, Frankfurter e Hand, trabalhavam conjuntamente com os docentes com vistas à solucionarem problemas que apareciam nas cortes de justiça.

Com efeito, na atualidade a mecanização do ato decisional, tornou muito difícil a existência de generalistas, pois o casuísmo impõe a necessidade de uma especialização maior,

\footnotetext{
${ }^{1}$ Em que pese ser possível se conhecer, na aplicação da doutrina realista para nosso direito de matiz continental exegética, o termo precedente como também se amoldando ao conceito de lei, para fins deste trabalho o precedente será restrito apenas aos precedentes jurisprudenciais.

2 O novo CPC, em vacatio legis, Lei n ${ }^{\circ}$ 13.105/2015, estabelece inúmeros precedentes “orientadores" aos magistrados, como por exemplo, nos incisos do art.332, no inciso VI, do art.489, e nos incisos do $\S 4^{\circ}$, do art.496, onde até mesmo "jurisprudência administrativa" impediria o exercício do duplo grau recursal obrigatório.

3 Súmulas vinculantes, reclamações contra turmas de juizados especiais criadas pelo RE 571.572-ED, etc.
} 
tanto que Posner (2011, p.245), adverte que nos EUA, a maioria dos casos que aprecem nos manuais da academia são escritos por secretários judiciais para os juízes. Ora, se essa atomização do direito com uma certa terceirização ${ }^{4}$, acontece em um sistema, como o americano, onde não há um problema tão sério no tocante a quantidade de demandas como passivo, há de se temer que no Brasil a necessidade de ser proferida a decisão, leve-se a uma perda qualitativa em homenagem aos números de produtividade.

O problema do paulatino incremento da mecanização da atividade dos juízes, representa um retrocesso da práxis (ação livre) para a poiesis (puro esforço de produção alienado), suprimindo do julgador não apenas a possibilidade de decidir por "opções políticas" e "pelas crenças ou ideologias", mas também pelo seu "lugar social” (FEITOSA, FREITAS, 2015, p.2 e 4), pelo seu estar no mundo.

A supressão do seu lugar social, de modificador da paisagem, é algo preocupante, pois, o juiz, como qualquer humano, sob o olhar da pedagogia freireiana (FREIRE, 2014, P. 101-103), é um ser inconcluso, consciente de sua inconclusão, o que afasta o tecnicismo "bancário", "imobilista" e "fixista" do descricionismo dogmático na concepção da jurisprudência mecanizada. Destarte, a interpretação "para ser tem que estar sendo" e nessa concepção problematizadora, histórica, com esteio em uma práxis provoca a necessidade de evolução permanente e prescritivista da atividade jurídica.

Essa práxis transformadora pode ser feita na atividade judicante, abandonando-se a metafísica sem compromisso com as consequências práticas da decisão. Como exemplo, basta se recordar que nos EUA, entre as décadas de 60 e 70 do século passado, por influência dos políticos de esquerda o realismo jurídico clássico do início do século foi potencializado de uma forma mais pretensiosa vindo posteriormente a construir um direito mais casuísta, a pretexto de uma teoria de ética de fins, que a título de garantir justiça social levaria a figura do Juiz Hércules $^{5}$ de Dworkin, inspirado em uma interpretação prescritivista pouco limitada.

\footnotetext{
4 Mesmo nas instâncias superiores pode se encontrar esse problema, fazendo com que a vinculação da magistratura possa ocorrer em relação a um caso não escrito por um magistrado.

5 Esse padrão se constituirá em um comportamento judicial que pode se amoldar a um ou mais dos seguintes padrões de comportamentos, vislumbrando por François Ost (OST, 2005: p. 169-172):

(a) Juiz Júpiter, é aquele amarrado ao "sagrado" do textualismo ou formalismo, dependente de uma lógica

jurídica dedutiva vinculada à segurança e ao monismo jurídicos. E, portanto, a lei é o ponto focal de onde irradia toda a justiça.

(b) Juiz Hércules, que toma para si a engenharia da mudança do tecido social com sua decisão, que seria o foco, e não a lei;

(c) Juiz Hermes, aquele padrão que representa a pluralidade de atores jurídicos e políticos, dado o tangenciamento entre essas esferas, permitindo a circulação de informações que permitem que a atividade interpretativa seja fluídica e ocupe os vazios das zonas cinzentas.
} 
Precisamente no capítulo VII, do seu Império do Direito, Dworkin (2007, p. 271273), adota a postura do direito como integridade, de modo a considerar "inútil" a diferenciação entre contexto de descoberta e contexto de justificação, isto é, seria irrelevante o debate se os juízes descobrem ou inventam o direito, pois sempre será necessário uma interpretação contínua.

Embora entenda que os elementos políticos argumentativos não possam servir de único lastro a uma decisão judicial, pela impossibilidade de sua confusão com argumentos de princípios, Dworkin (2010, IX) sustenta que a teoria da decisão não se limita a descrever a simples atividade, mas também a dizer como a mesma deveria se desenvolver para o futuro, o que acarreta necessariamente uma visão prescritivista da teoria da decisão judicial.

Observe-se que do ponto de vista externo, seja contemplativo ou dos demais operadores jurídicos, a decisão judicial em primeira instância, pode ser vislumbrada como descritivista, já que não poderia qualquer deles interferir no ato, normalmente solitário de julgar. Porém, em relação ao aplicador a atividade jurisdicional pode ser prescritivista, notadamente em hard cases, não se resumindo a uma mera descrição silogística do que é, pois o intérprete autêntico pode ir além de modo a elastecer os parâmetros do "ser" para o "dever ser".

Contudo, mesmo que não se aceite a prática decisional de atividade essencialmente prescritivista, a pluralidade de entendimentos decorrentes da interpretação de regras (aplicação na lógica binária do "tudo ou nada" e impossibilidade de coexistência antagônica) e princípios (aplicação ponderada e possibilidade de coexistência antagônica) não podem justificar uma única solução para os casos judiciais, a prejudicar o estabelecimento do precedente único. Pois, como já advertido na filosofia de Holmes, destacada por CARDOZO (2004a, p. 32-38) é imperiosa a necessidade de afastamento da noção de direito único e imutável a ser descoberto e não criado, razão pela qual, decorre a necessidade do entendimento de que a técnica da predição par excellence funcionaria como bússola a permitir se antever como os tribunais decidirão causas futuras.

Importante destacar que a decisão judicial não deve ser considerada como produto de um contexto de descoberta, mas, de um contexto de justificação que opera como fundamentação política do direito, como percebido por Enoque Feitosa (2009, p. 44-45), com esteio em Wróblewski, ao reconhecer que o exame adequado da forma jurídica exige uma refinada justificação interna semelhante ao mito da divindade romana Janus.Por esse motivo, é imperativo que a cada novo julgamento o aplicador afaste o risco de se atrair pela ilusão de seguir 
o ritual de uma jurisprudencia mecânica Mechanical Jurisprudence (POUND， 1908， p. 605623), onde se encaixaria o precedente ao caso,

independente do contexto fático a ser enfrentado, o olhar deve ser bifronte para o passado e para o futuro.

No entanto, a interpretação jurídica pela técnica realista não pode ser confundida com o que se denominou decisionismo ou até mesmo de ativismo ${ }^{6}$ pois esses últimos entendem o processo decisional com duas etapas na qual a primeira descreveria o comportamento dos magistrados e na segunda, prescreveria o direito dictum nos Tribunais como sendo o padrão que deva ser seguido sempre, embora o ativismo admita limites principiológicos extremos, além das regras.

Para os fins deste trabalho, objetivando encontrar diferenças e pontos de tangenciamento entre a concepção descritivista e prescritivista, serão utilizadas as duas obras pragmáticas e resultado de conferências de Benjamin Cardozo "Evolução do Direito" e a “Natureza do Processo Judicial' em contra ponto a obra, há que se reconhecer, bem mais vasta e sistematizada de Ronald Dworkin, do qual fora analisadas precisamente o clássico "Levando Direitos a Sério", complementado com “O império do Direito" e "Uma Questão de Princípio".

6 No direito europeu não se usa a expressão "juiz ativista", mas "juiz militante". 
Benjamin Cardozo logo no início de sua clássica obra a "Natureza do Processo Judicial", demonstra que ao examinar o que fazem os juízes nos "Caldeirões do Tribunais" ao decidirem causas, aponta a presença de uma angustia inicial que aflige o intérprete quanto a necessidade de aplicar, recusar ou criar um precedente.

Com efeito, mesmo em uma concepção positivista o precedente pode não mais se justificar por estar defasado ou até por se deparar o intérprete com circunstâncias e elementos fáticos ainda não enfrentados pela decisão ou normatização original que podem provocar estranhamento no trato da regra de reconhecimento.

Torna-se recomendável, assim, se ter em mente que a inafastabilidade da prestação jurisdicional, para o aplicador, não se refere a imposição de proferir qualquer decisão, mas no enfrentamento e expiação pelo "sofrimento de escolher, a cada passo o nosso caminho" (CARDOZO, 2004a, 45), exigindo que ele pondere a pertinência na utilização dos métodos da: filosofia, história, costume e sociologia, já apontados na primeira e segunda palestras da “Natureza do Processo Judicial” (2004b, p.18).

Uma preocupação que não se pode olvidar, é que a construção do direito, não deve se dissociar da equidade e da justiça, mesmo em prejuízo, algumas vezes dos vínculos decorrentes da lógica e da história, pois a desconsideração dos interesses sociais, do bem comum, traria perdas maiores que as vantagens. Neste sentido a ciência jurídica seria uma interrelação de saberes jurídicos, construída em vários ângulos possíveis. (SALDANHA, 1974, p.32).

A dogmática é, portanto, insuficiente, pois esses campos acima mencionados levam ao posicionamento do juiz como refém de uma consciência social que está inserido, em uma permeabilidade que agrega circunstâncias históricas e sociológicas que faz com que ele reconstrua, de acordo com as objetivações da mente, com sua visão de mundo, os significados contidos nas formas significativas da realidade estudada, como percebeu Cardozo (2004a, p. 64), ao afirmar que o juiz "auxilia a formação e a modificação da consciência que interpreta", pois a descoberta e a criação reagiriam mutuamente.

O referido Juiz da Suprema Corte Americana critica os partidários da rígida separação entre poderes, pois inadmite a perpetuação de um precedente quando este seja "tão bolorento quanto o túmulo do qual ele havia sido retirado para enfrentar a luz de uma nova era" 
(CARDOZO, 2004a, p. 86-88), pois “a adaptação da regra ou princípio às combinações variáveis de acontecimentos exige a ação criadora do juiz".

Essa tarefa criadora do juiz é observada por Dworkin (2011, p. 128-129), não apenas para lacunas, mas para os chamados "casos difíceis"”, e seria analisada no que denominou ser a teoria da controvérsia, que estabeleceria os padrões a serem utilizados pelos aplicadores na aplicabilidade de direitos fundamentais que poderiam, neste caso, "agir como se fossem delegados do poder legislativo, promulgando as leis que, em sua opinião, os legisladores promulgariam caso se vissem diante do problema". ${ }^{8}$

Aqui, desde logo, se observa que para Dworkin (2000, p. 215-216) sempre haveria um "única resposta correta” para o problema jurídico pois seria " improvável que duas teses difiram a ponto de exigir resposta diferentes em algum caso e, ainda assim, adequar-se igualmente bem ao conteúdo jurídico relevante".

Todavia, a unicidade da resposta vislumbrada por Dworkin não é de fato considerada, pois se o direito evolui e seus aplicadores não possuem a mesma percepção do momento evolutivo, embora inseridos no mesmo contexto histórico ou costumeiro, é natural que exista divergências de entendimentos.

Por outro lado, a simples concepção descritivista implicaria em subalternatividade da função judicante à função legislativa, indicando que o processo judicial está para ficar, pois não se pode garantir que a escolha feita por um comitê legislativo seja melhor do que a escolha feita pelos magistrados (Cardozo, 2004b, p. 87-88), até mesmo porque os últimos são profissionalmente mais preparados para observarem situações fáticas dentro de um contexto de realidade e não de simples possibilidade.

\footnotetext{
7 Que surgem no caso de normas de texturas abertas, lacunas legais, ou que imponha escolhas.

8 Ressalvando que a efetivação de direitos fundamentais para Dworkin não significa substituição de vontade política dos demais poderes.
} 
No Brasil, onde a legitimidade do processo de escolha dos nossos legisladores é apenas formalmente democrático ${ }^{9}$, a crítica a falta de controle ou avaliação popular dos juízes a justificar a imposição de stare decisis, deve ser vista com desconfiança, pois se não pode o Judiciário permanecer intangível as críticas, não há como se permitir seu acanhamento como se fosse invasor do entendimento legislativo, mesmo que descompassado com a realidade.

As leis, portanto, são predições de primeiro grau que realizam um papel marginal nas decisões judiciais, em se tratando de hard cases, devendo ser interpretadas dentro de um certo ceticismo decorrente do pragmatismo observado pelos realistas jurídicos.

É impossível a previsão de todas as situações hipotéticas que necessitem de regulação e mesmo se pudessem ser previstas a evolução constante e as peculiaridades fáticas já seriam suficiente para mostrar a necessidade de revisão constante e de individualização o que é impossível ao poder legislativo.

\section{0 precedente e a falsa certeza}

Se no direito medieval a Summa Codicis do glosador Azo era a referência a qualquer pessoa que fosse aos tribunais (CARDOZO, 2004a, p. 16), na atualidade com a proliferação de ferramentas de buscas do que se pode denominar de "jurisdição tipo folios ${ }^{10}$ ", no qual o precedente dos tribunais é buscado pelos interpretes através de palavras-chave como um standard suficiente para justificar a decisão da causa em um automatismo que compromete, muitas vezes, a legitimidade e eficácia do julgamento.

\footnotetext{
9 Não se pode afirmar categoricamente que os votos dados aos deputados e senadores no Brasil sejam, em sua maioria, por convicção. Na maior parte das vezes é apenas o resultado de combinações de chapa de lideranças locais onde os cargos legislativos serviriam de "posições de reserva" para seus ocupantes posteriormente almejarem cargos executivos nos três níveis de federalismo.

10 Referência ao programa pioneiro no Brasil de busca de sites de jurisprudência o Folio Views da Folio Corporation, que hoje encontra concorrência nos aplicativos padrões Delphi.
} 
Cardozo (2004b, p. 10-11) no entanto, critica o simplismo da técnica do buscar e seguir, ao afirmar que se esse procedimento garantisse as melhores decisões "o homem que tivesse o melhor fichário de casos seria também o juiz mais sábio", pois "cada julgamento tem um poder gerador. Ele gera a sua própria imagem”.

É que as verdades dos precedentes não são conclusivas, e, sendo assim, a certeza atingida por um método descritivo, nem sempre é real, pois são apenas paradigmas de avaliação que podem ser sopesados e mensurados quanto aos critérios de adequação a situação posta em exame na busca por justiça.

Mesmo sabendo disso os aplicadores, muitas vezes, se contentam com o horizonte limitado do formalmente correto, sacrificando-se a certeza decorrente da busca pela verdade real, tanto pela dificuldade de romper padrões de inércia como pelo fato de não ser visto com muita simpatia a revisão de assentamentos já existentes, razão pela qual há necessidade de não se contentar com a estagnação hermenêutica, pois exemplifica Cardozo (2004a, p. 18), que o precedente é apenas a estalagem da jornada da justiça, que evoluirá sempre, no dia seguinte, no calendário da jurisprudência.

Neste prisma a predição nunca será uma conclusiva, mas tão somente uma profecia que por ter natureza indutiva pode ou não se tornar uma verdade. Para o nosso sistema processual civil, que privilegia a inércia judicial como um vestuso critério garantista de imparcialidade, o simples formalismo é suficiente para garantir uma roupagem à decisão, de modo que ela se amolda perfeitamente a técnica de predição.

Entretanto em matéria penal, administrativa e em decisões de tribunais superiores as diferenças entre posicionamentos ou inconsequências visualizadas pelo pragmatismo podem afetar a própria legitimação do Poder, já que as partes esperam que causas semelhantes tenham resultados semelhantes.

A lógica impiedosa, percebida por Cardoso (2004a, p. 44), não pode sacrificar a verdade aos "deuses da jurisprudência" criando um "trabalhador medíocre (2004a, p. 61), devendo o processo interpretativo além dos elementos dos fatos e consequências sociais ter o elemento intuitivo do magistrado, não uma intelecção arbitrária e simplesmente volitiva, mas decorrente da utilização da axiologia aplicada na solução de problemas éticos, sociais e estéticos.

A atividade jurídica como prescrição não é arbitrária ou política, pois esta última se insere no "caldeirão" que forja, junto com os demais influxos, a atualização da jurisprudência.

As certezas contidas no stare decisis não garantem imutabilidade no futuro e portanto não podem ser consideradas reais e suficientes para uma aplicação cega pelo intérprete 
de modo a exigir, sob o risco de incorrer em sério erro, que suas "realidades" sejam cotejadas e examinadas não apenas do ponto de vista da dogmática, mas também da zetética, de modo a se conhecer se podem ou não ser aplicadas a um fato novo.

\section{A insuficiência da discricionariedade interpretativa.}

Se esse exame da prestabilidade do precedente pode ser feito pelo magistrado, poderia ele extrapolar, em uma ética de fins, os limites da lei de modo a criar um novo direito?

O positivismo admite a criação da regra específica no caso de lacunas, todavia o ativismo $^{11}$ permite uma melhor extensão de tal poder criacionista, embora tangencie mais facilmente elementos metajurídicos que vão além do olhar externo prescritivista.

Em sua crítica ao positivismo de Hart, Dworkin (2011, p. 51-63) procura justificar a utilização da discricionariedade dividindo-a em categorias de modo a permitir que em alguns contextos ela possa ser utilizada. Ele afirma que a discricionariedade pode ter dois sentidos, um primeiro, considerado fraco, se vincularia a hipótese de que as decisões a serem tomadas dependeriam de padrões estabelecidos, se constituindo figurativamente em um "espaço vazio, circundado por uma faixa de restrições" a permitir uma gama de diversidades de decisões ou, ainda, a falta de censura de autoridade superior a torna-la definitiva.

Por outro lado, haveria também o sentido forte, que seria aquele em que os deveres não impõe a tomada de uma decisão específica e poderia ser aplicado nos chamados hard cases (casos difíceis).

Mesmo assim, haveria a possibilidade dos princípios modificarem regras quando tal alteração fortaleça algum princípio, não admitindo, entretanto Dworkin (2011, p.60) que "esse critério não pode depender das preferências pessoais do juiz".

\footnotetext{
11 Para os fins deste artigo o ativismo será considerado em cotejo com o realismo, desprezando-se o decisionismo, tendo em vista a carga empiristica que o acompanha.
} 
A hermenêutica jurídica como método prescritivo não implica em incorrer no escorregadio campo do arbítrio. A prescrição não é valorativa no sentido estritamente pessoal do intérprete. De fato não há espaço para o voluntarismo descomedido e arbitrário. Entretanto igualar o ativismo ao pragmatismo como herdeiro do realismo jurídico, seria igualar comportamentos decisionais diferentes, pois entre o prescrever a nova norma concreta a partir de parâmetros interpretativos e contextuais claros e se criar teratologias sem qualquer limites, vai uma distância muito grande.

A decisão não é boa ou ruim porque o aplicador politicamente quer que ela seja boa, ou ruim, não, a atividade prescritivista aqui defendida é bem mais complexa, pois depende de todo um arcabouço metodológico que reconheça os pré-conceitos do intérprete e sua imersão na paisagem social, econômica e histórica que ilumina o horizonte jurídico.

Por outro lado, a atividade hermenêutica permite um olhar contemplativo de como se dá o processo decisional ou um exame intervencionista. De tal forma fica impossível se separar padrões de moralidade pública da "moralidade pessoal” do intérprete quando não exista regramento anterior capaz de dirimir a controvérsia.

O moralmente bom, ou moralmente mau como percebido por Kelsen (2009, p. 7778), está em constante modificação, logo não há que se exigir que o direito se reflita em um parâmetro de moral absoluta, demonstrando a aplicação jurisprudencial sob uma legitimação acrítica em violação à Teoria Pura do Direito. O Direito não precisa se justificar na moral para existir e ser cumprido.

Kelsen, portanto, não admite submissão do direito a uma moral absoluta ou relativa, mas apesar de admitir que a interpretação do direito é ato de vontade (KELSEN, 2009, p. 394), não chega a resolver o problema já percebido pelos realistas jurídicos norte-americanos de que os elementos inconscientes utilizados pelos juízes na interpretação autêntica trazem concepções de moralidade decorrentes de sua formação e visão de mundo que extrapolam os limites da moldura positiva.

Observe-se que a interpretação judicial, não se trata de uma interpretação externa, filosófica, metafísica, sobre o direito, mas uma interpretação essencialmente no direito, visto que a práxis está presente na atividade jurisdicional.

Com efeito, é possível a aplicação dos valores pessoais do juiz, tão somente na hipótese de, inexistindo precedente, os standards objetivos da comunidade forem diferentes dos pessoais do aplicador, a vontade objetiva estará imersa na subjetiva (CARDOZO, 2004a, p. 63) desde que esses elementos pessoais possam ser trabalhados dentre um dos métodos que exemplificou para a natureza do processo judicial. 
Cardozo indica que o magistrado se depara com um problema que exige duas abordagens. A primeira seria encontrar a ratio decidendi depois deve indicar em que caminho ela deve se desenvolver, todavia esse desenvolvimento não é ilimitado, já que com escólio em Holmes (CARDOZO, 2004b, 40-50), indica a existência de um limite de "compilação" ao poder criador do juiz:

\begin{abstract}
Reconheço, sem hesitação, que os juízes devem legislar, e de fato legislam, mas só o fazem de maneira intersticial; estão limitados a movimentos que vão do molar ao molecular. (...) Essa concepção de que a prerrogativa legislativa de um juiz opera entre espaços assemelha-se à teoria das" lacunas do Direito", que é familiar aos juristas estrangeiros. "A estrutura geral fornecida pela lei escrita deve ser preenchida, em cada caso, por meio da interpretação, ou seja, observando-se os princípios da lei escrita. Em todos os casos, sem exceção, é tarefa de o tribunal prover o que a lei omite, mas sempre por meio de uma função interpretativa.
\end{abstract}

Como se observa o próprio Cardozo se refere a possibilidade de modificação de regras por princípios que vão além da interpretação descritivista considerada "fraca". No entanto, Dworkin, não admite a existência de regra de reconhecimento (pedigree) para identificação de princípios, e de tal forma a obrigação jurídica existiria somente quando as razões favoráveis a sua existência fossem mais fortes que as razões contrárias, o que parece um tanto tautológico.

A discricionariedade positivista, portanto, não conduz a lugar nenhum em face da necessidade de sopesamento de princípios. De toda forma, positivista ou não, as convicções pessoais do intérprete seriam o prisma sobre o qual se examina o espectro de cores da realidade e como tal, dependem de uma lapidação particular dada pela teoria que examina o fenômeno, de modo que todas as nossas convicções, segundo Dworkin (2000, p.254-255), “confrontam a experiência em conjunto, com um sistema interdependente, e não há nenhuma parte desse sistema que não possa, em princípio, ser revista e abandonada se estivermos dispostos e formos capazes de rever e ajustar o restante".

Ao analisar a crítica clássica a teoria dos direitos a partir do modelo de Juíz Hércules, que segundo Dworkin iria buscar o direito correto além da lei, percebendo que além de direitos políticos haveria direitos morais. Neste ponto pode se observar a existência de dois aspectos em sua teoria: um descritivista, outro prescritivista. O primeiro representaria a "estrutura atual da instituição da decisão judicial”, e o aspecto normativo se constituiria em uma "justificativa política" para essa estrutura.

$\mathrm{Na}$ análise da justificativa política entretanto sustenta Dworkin (2011, p. 197) que não há que se intuir que o Juiz Hércules haveria de escolher entre "suas próprias convicções 
políticas e aquelas que ele considera como as convicções políticas do conjunto da comunidade", pois na verdade ele teria uma concepção particular de moralidade comunitária que seria aquela "moralidade política que as leis e as instituições da comunidade pressupõem", admitindo, portanto, a possibilidade de diversidade de entendimentos:

A história deixa claro que muitas das decisões de Hércules sobre os direitos jurídicos dependem de juízos de teoria política que poderiam ser emitidos diferentemente por diferentes juízes, ou pelo público em geral. (Dworkin, 2011, p. 192)

O juiz segundo Dworkin para garantir os direitos das minorias deve analisar as raízes históricas mesmo hegemônicas em busca da integridade ${ }^{12}$ obstacularizando a tirania da maioria.

Neste contexto, impõe-se que abandone as políticas públicas, pois não exerce administração pública devendo levar a sério os direitos dos sub-representados, não podendo imaginar que pelo simples entendimento do bem estar coletivo se esteja assegurando os direitos individuais dos indivíduos.

Em nome da salvaguarda dos direitos das minorias a teoria de Dworkin não se conforma com o pragmatismo pois o veria apenas como em uma faceta utilitarista.

A falibilidade judicial ${ }^{13}$ é um vetor que deve ser considerado sempre como presente, entretanto esse risco não pode servir de obstáculo a se admitir a técnica do Juiz Hércules, pois esta fomenta a prolação de juízos sobre direitos institucionais, afastando o non liquet e a acomodação que levaria a não se preocupar com a prolação de decisões justas, afinal não há possibilidade de submeter as decisões a outra instituição ou poder, devendo no entanto servir de advertência de que seu entendimento pode está errado nos juízos políticos, de modo a impor o dever de decidir os hard cases com bastante humildade.

A essa objeção pouco importa que a decisão seja de princípio, e não de política. Importa apenas que seja uma decisão sobre matéria de convicção política, a propósito da qual os indivíduos razoáveis não cheguem a um consenso. Se Hércules decide casos com base em tais juízos, então decidem com base em tais convicções e preferências, o que parece injusto, contrário à democracia e ofensivo ao princípo geral de direito. (Dworkin, 2011, p. 192-193)

\footnotetext{
12 No caso norte-americano seria a mens legistoris dos pais fundadores, os "federalistas".

13 (DWORKIN, 2000, 254-255): [...] é uma tese conhecida nessa disciplina que nenhuma das convicções que temos, sobre o mundo e o que está nele, nos é imposta por uma recalcitrante realidade independente da teoria; de que as opiniões que temos são mera consequência de termos aceitado alguma estrutura teórica particular. Segundo uma versão proeminente desse ponto de vista, todas as nossas convicções sobre lógica, matemática, física etc. confrontam a experiência em conjunto, com um sistema interdependente, e não há nenhuma parte desse sistema que não possa, em princípio, ser revista e abandonada se estivermos dispostos e formos capazes de rever e ajustar o restante.
} 
O pragmatismo é visto como utilitarismo, entretanto desconsiderou o Professor da New York University School of Law que o pragmatismo que serviu de matiz para o realismo e para a própria jurisprudência sociológica tem foco no contexto pessoal e social em que está inserido o aplicador, portanto não é um pragmatismo ativista, embora de natureza prescritivista.

Para a transparência do processo de criação da norma concreta, o pré-conceito lógico permite uma expectativa, que pode se confirmar ou não, de acordo com o evoluir da cognição, mas torna-se imprescindível para essa alteridade que o intérprete ponha em jogo seus conceitos prévios, influenciando e sendo influenciado em um feed-back.

Nessa construção decisional com base em uma práxis relativa, há que se reconhecer como sustentado por FEITOSA e FREITAS (2015, p. 9), ao analisar a $11^{\text {a }}$ Tese de Marx ad Feuerbach, contida na Ideologia Alemã, que "os interesses particulares coincidam com os interesses humanos, pois se o ser humano é formado pelas circunstâncias é necessário que essas sejam formadas humanamente".

Com fundamento nesse pensamento, é necessário que a visão de mundo do juiz ao decidir uma causa, para justificar a postura prescritivista não limitada pelo precedente, deva coincidir com uma visão de justiça social que suplante o simples personalismo, que poderia ser confundido com o mero decisionismo, sempre frágil em seus fundamentos. Esse equilíbrio, certamente, se constitui no maior desafio em uma época de padronização de condutas, inclusive judicantes.

\section{Conclusão}

A complexidade das relações sociais impõe a evolução do direito e consequentemente não há como se sustentar uma teoria da decisão judicial que seja estanque e não possa se amoldar a novas realidades. $O$ direito pode ser prescritivo, e o de fato ao materializar-se em uma sentença o é, pois a concretude de sua efetivação impõe a necessidade de mutabilidade.

Neste contexto a hipervalorização dos precedentes colocados como máximas a serem seguidas pela magistratura pátria, sobretudo a de primeiro grau, deve ser vista com reservas pois não há como se garantir que a imposição do stare decisis regulador de situações pretéritas possa ser apreciado como normatização futura.

Há, assim, necessidade de criação de um direito novo para sanar não apenas lacunas, mas também incoerências sistêmicas, estas entendidas como incompatibilidade conflituais entre 
princípios que não podem ser solucionados pelas regras positivistas para as antinomias como as de completude e de coerência.

Este novo direito, quem sabe um precedente, deve buscar se amoldar a limites principiológicos ou normativos, através de regras de ponderação e razoabilidade aplicadas entre perdas e ganhos, uma vez que a discricionariedade não bastaria a si mesma por depender de fatores externos que as limitem.

Entretanto, não há que se confundir essa limitação com a adoção de standards metajurídicos travestidos de argumentos econômicos ou sociológicos, daí a contribuição do realismo, ao focar a fonte do processo interpretativo no próprio sujeito hermenêutico, isto é, o juiz por excelência.

Os sistemas interpretativos pode e deve se utilizar de elementos filosóficos zetéticos do costume, da história e da sociologia, que não se confundem com meras políticas voluntaristas; todavia tais elementos externos precisam ser percebidos, cotejados e desenvolvidos a partir dos elementos inconscientes resultantes da formação do julgador.

O olhar do julgador, portanto, nunca será descritivamente externo e sua atividade não pode ser comparada ao empirismo do amador, decide porque tem que fazê-lo, e sua formação e suas experiências diárias lhe garantem um preparo mais adequado para decidir direitos dos cidadãos em conflito do que teria um legislador.

A deficiência apontada de falta de um controle político, pela ausência de escolha de seus membros por eleição popular, chega ser falacioso, pois além da escolha dos membros dos tribunais superiores depende exclusivamente no caso do STF, e primordialmente no caso do STJ de uma vontade política de eleitos democraticamente.

Por outro lado, a mutabilidade de governos necessariamente no Brasil demonstra que a vontade popular a legitimar um congresso é muito mais retórica que técnica, pois o que vemos são pluralidade de vontades organizadas e dirigidas por lobbies com apenas um acesso temporal que lhe dê um verniz democrático, nunca servindo para garantir um perfil crítico ao governo posto (salvo se desagradar interesses econômicos), fazendo com que nossa história a seletividade de forças tenha ocorrido muito mais por rupturas do que pelo debate democrático.

Nesse prisma a atividade jurisdicional produz, amolda e modifica o direito a todo instante, não porque deveria fazê-lo, mas porque a prática o exige ante a impossibilidade de juízos absenteístas que a causa seja decidida.

O debate portanto se os juízes deveriam agir na estrita obediência ao precedente, perde, apesar das reformas, a cada dia mais, o sentido, pois muito mais que se indagar as razões de agirem de uma forma ou de outra, é melhor admitir que isso, como atividade prescritivista, 
é uma realidade e tentar identificar os vetores pessoais utilizados pelo mesmo como forma de predicar novos posicionamentos.

Esse poder de criação do direito, não pode ser absoluto e descontextualizado, deve evoluir como a vida afastando-se dos tests mecânicos, reconhecendo que a certeza será sempre um ideal inatingível, que não impede, contudo, que o aplicador eleve os olhos dos limites de sua "paróquia" para atingir voos infinitos na tentativa de se chegar a uma melhor certeza, pois, como destaca Cardozo (2004a, p. 92)“o direito deve ser estável, mas não pode permanecer imóvel”.

O aplicador do direito necessita, portanto, resolver o conflito que lhe surge nas mãos, enfrentando o medo inafastável de falhar para esclarecer mesmo que com a criação de uma "regra nova" contrária a precedentes superiores ou históricos, tendo como norte os fins sociais, o bem comum, na solução de hard cases.

A atividade jurisdicional somente é coletiva em órgãos colegiados, e a imposição de entendimentos rotulados ofende a própria concepção de órgão judicial autônomo que caracteriza cada membro da magistratura; não servindo a necessidade de previsibilidade de justificativa para impor precedentes vinculantes e estanques como forma de apertar as amarras da atividade jurisdicional; uma vez que, principalmente para os juízes, a interpretação depende de uma práxis, que não se limita ao descritivismo, de modo que é possível, ante a vastidão da jurisprudência, mesmo com o precedente, ir além da citação de Nelson Saldanha (1974, p. 44), inspirada em Erico Veríssimo, e afirmar que: “o resto, portanto, não é silêncio". 


\section{REFERÊNCIAS}

BOBBIO, Norberto. Teoria do ordenamento jurídico. Trad. Maria Celeste C. J. Santos. Brasília: Editora Universidade de Brasília, 6. ed., 1995.

Teoria da Norma Jurídica. Trad. Fernando Pavan Baptista e Ariani Bueno Sudatti.

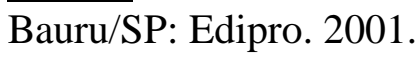

CARDOZO, Benjamin N. Evolução do direito. Trad. Henrique de Carvalho. Belo Horizonte: Lider, 2004.

. A natureza do processo judicial: palestras proferidas na universidade de Yale. Trad. Silvana Vieira; Rev. Téc. Trad. Álvaro de Vita. São Paulo: Martins Fontes, 2004.

DWORKIN, Ronald. Uma questão de princípio; Trad. Luís Carlos Borges. São Paulo: Martins Fontes, 2000.

2010.

Levando os direitos a sério. Trad. Nelson Boeira. São Paulo: WMF Martins Fontes, 2007.

.O império do direito. Trad. Jefferson Luiz Camargo. 2.ed, São Paulo: Martins Fontes,

FEITOSA, Enoque. A Crítica Marxista ao direito e o Problema Da Interpretação. Disponível na internet:

http://www.unicamp.br/cemarx/anais_v_coloquio_arquivos/arquivos/comunicacoes/gt2/sessa o1/Enoque_Feitosa.pdf. Acesso em 15 ago. 2015.

O discurso jurídico como justificação: uma análise marxista do direito a partir da relação entre verdade e interpretação./ Enoque Feitosa Sobreira Filho. Recife: Ed. Universitária da UFPE, 2009.

; FREITAS, Lorena. Para uma crítica ao moralismo jurídico sob a perspectiva da filosofia da práxis: a forma jurídica, entre descrição e prescrição. Anais do VIII Colóquio Internacional Marx \& Engels. Instituto de Filosofia e Ciências Humanas - UNICAMP, Vol.1, $\quad \mathrm{n}^{\circ} \quad 1, \quad 2015.2$ Disponível em: http://www.ifch.unicamp.br/formulario_cemarx/selecao/2015/trabalhos2015/enoque\%20feitosa\%20e\% 20lorena\%20freitas\%2010582.pdf. Acesso em 16 ago.2015.

FREIRE, Paulo. Pedagogia do oprimido. 58 ed. Rio de Janeiro: Paz e Terra, 2014.

KELSEN, Hans. Teoria pura do direito. Trad. João Baptista Machado. São Paulo: Editora WMF Martins Fontes, $8^{\text {a }}$. Ed. 2009.

MARINONI, Luiz Guilherme. Precedentes obrigatórios. São Paulo: Editora Revista dos Tribunais, 2010.

MARX, Karl ; ENGELS, Friedrich. A ideologia alemã. Trad. Rubens Enderle, Nélio Schneider e Luciano Cavini Martorano. São Paulo: Boitempo Editorial, 2007. 
OST, François. Jupiter, Hércules, Hermes: Tres modelos de Juez. In: Cervantes Virtual. Disponível

em:

http://www.cervantesvirtual.com/servlet/SirveObras/01360629872570728587891/cuaderno14 /doxa14_11.pdf. Acesso em 20 set. 2013.

POUND, Roscoe, Justiça conforme a lei; Trad. E. Jacy Monteiro. $2^{\text {a }}$ ed. Ibrasa, São Paulo: 1976.

Mechanical Jurisprudence. Columbia Law Review, 1908, 605-623. Disponível em: https://archive.org/details/jstor-1108954. Acesso em 30 jul. 2014.

Las grandes tendências del pensamento jurídico. Trad. José Puig Brutau. Granada:

Editorial Comares, S. L. 2004.

POSNER, Richard A. Cómo deciden los jueces. Trad. Victoria Roca Pérez; Madrid: Marcial Pons, 2011.

RODRIGUEZ, César. La decisión judicial. El debate Hart y Dworkin - estudio preliminar. Bogotá: Siglo Del Hombre Editores: Facultad de Derecho, universidad de los Andes, 1997.

SALDANHA, Nelson Nogueira. Velha e nova ciência do direito. Recife: Editora Universitária - Universidade Federal de Pernambuco, 1974. 